\title{
Advanced Systems Data for Mapping Emperor Penguin Habitats in Antarctica
}

By Richard D. Sanchez'; Gerald L. Kooyman ${ }^{2}$

Open-File Report 2004-1379

'Eastern Region Geography, Regional Investigations Team, Reston, VA 20192

${ }^{2}$ Scripps Institution of Oceanography, University of California-San Diego, La Jolla, CA 92037

U.S. Department of the Interior

U.S. Geological Survey 
Advanced Systems Data for Mapping Emperor Penguin Habitats in Antarctica

\author{
Richard D. Sanchez \\ U.S. Geological Survey \\ 521 National Center \\ Reston, VA 20192
}

\author{
Gerald L. Kooyman \\ Scripps Institution of Oceanography \\ University of California - San Diego \\ La Jolla, CA 92037
}

\begin{abstract}
Commercial orbital sensor systems combined with other resource data from the U.S. Geological Survey National Civil Applications Program (NCAP) may offer an effective way of mapping Emperor penguin habitats and their response to regional climate change in Antarctica. This project examined these resources to determine their applicability for mapping Emperor penguin habitats to support the National Science Foundation. This work is especially significant to investigate satellite-based imaging as an alternative to intrusive in-the-field enumeration of Emperor penguins and the potential of applying these procedures to support The National Map (TNP).
\end{abstract}

\title{
Introduction
}

The mapping and monitoring of habitat change in ecosystems in the Antarctic is highly dependent upon a continuous source of high-quality and high-resolution spatial data. Acquiring a continuous source of reliable data to aid in understanding, quantifying, and predicting how these ecosystems function and respond to regional climate warming is vital to scientists in maintaining a highly effective long-term monitoring program.

In 2001, the Antarctic Biology and Medicine Program, National Science Foundation (NSF), Arlington, Virginia, joined the U.S. Geological Survey (USGS), Reston, Virginia, to investigate orbital sensor data for acquiring enumeration data of Emperor penguins in the Ross Sea area of Antarctica. The ultimate goal of this project, in support of NSF grantee Dr. Gerald "Jerry" Kooyman, Scripps Oceanographic Institute, is to be able to monitor the affect of regional climate change on the Emperor penguin habitats.

High-resolution sensor data collected by commercial satellites like DigitalGlobe (QuickBird) and OrbImage (OrbView-3) offer fast and continuous wide-area coverage in Antarctica. DigitalGlobe imagery was collected over selected monitoring sites in the Ross Sea area in 2001 through 2003. The researchers used other resources from the USGS National Civil Applications Program (NCAP) to supplement the DigitalGlobe data.

Previous attempts to develop population counts of Arctic and Antarctic wildlife are well documented. In 1988 Graham Robertson, as part of the $35^{\text {th }}$ ANARE expedition to Mawson, applied various platforms to count Emperor penguins including stepladders and

Any use of trade, product, or firm names is for descriptive purposes only and does not imply endorsement by the U.S. Government. 
cameras hung from a helium-filled balloon (Robertson, 1990). Comparing counts made by observers on the ground with photographs from the remotely operated camera, Robertson and his colleagues calculated that on very cold days as many as 10 Emperor penguins could huddle within one square meter of space. Huddling by male Emperors which usually form in late July and early August is the most efficient way of minimizing space between themselves and keeping warm during the long incubation fast, since the warmer they are the longer their fat lasts.

Due to the lack of low sunlight, the researchers could not obtain satellite images of these huddle formations in the winter months of July and early August. In addition, two attempts to collect geodetic ground control data of Cape Crozier, the primary project site, were unsuccessful. Consequently, we aborted the development of an orthobase and automated method for counting Emperors in huddles. Instead we used October and September satellite images of disbanded huddles and applied GIS point data entry and retrieval operation.

A detailed explanation of the NCAP data used in this study is not possible because of its unique nature. See the references for Civil Application Committee (CAC) published bulletins released to the public for specific information about the use of the NCAP and related Imagery Derived Products (IDP's) and Global Fiducials Program (GFP):

\section{Project Test Area and Source Data}

The primary project area, Cape Crozier, is located in the vicinity of the Ross Sea (figure1). In addition to the project area, the authors previewed Beaufort Island, Cape Washington, Cape Roget, Coulman Island, and Franklin Island.

The home base of the project, McMurdo Station, is a year-round U.S. Antarctic base operated by Ratheon Corporation under contract with the NSF. Cape Crozier as well as most sites in the Ross Sea vicinity is usually reached by helicopter or Twin-Otter aircraft. With few exceptions, permits are required to work or visit these sites under the Antarctic Conservation Act of 1978, Public Law 95-541. The NSF, which administers the act, issued the necessary permits to conduct the fieldwork.

The Quickbird satellite data (1-m resolution panchromatic and 4-m resolution multispectral images) were collected for this project during October 2002 and September 2003. Supplemental data were acquired from the NCAP and the U.S. Antarctic Resource Center (US-ARC). The primary image processing and mapping components were ERDAS Imagine 8.5 (including Arc-structured Vector Module), ArcGIS 8.1, and SOCET Set 4.4 photogrammetric software.

\section{Field Surveys}

To verify the accuracy of the satellite count, Jerry Kooyman and fellow biologists manually counted selected Emperor groups during the 2001, 2002, and 2003 summer

field seasons. The researchers attempted to conduct the counts during the satellite flyover 
to minimize variation. However, because penguins move throughout the day, some fluctuation was expected.
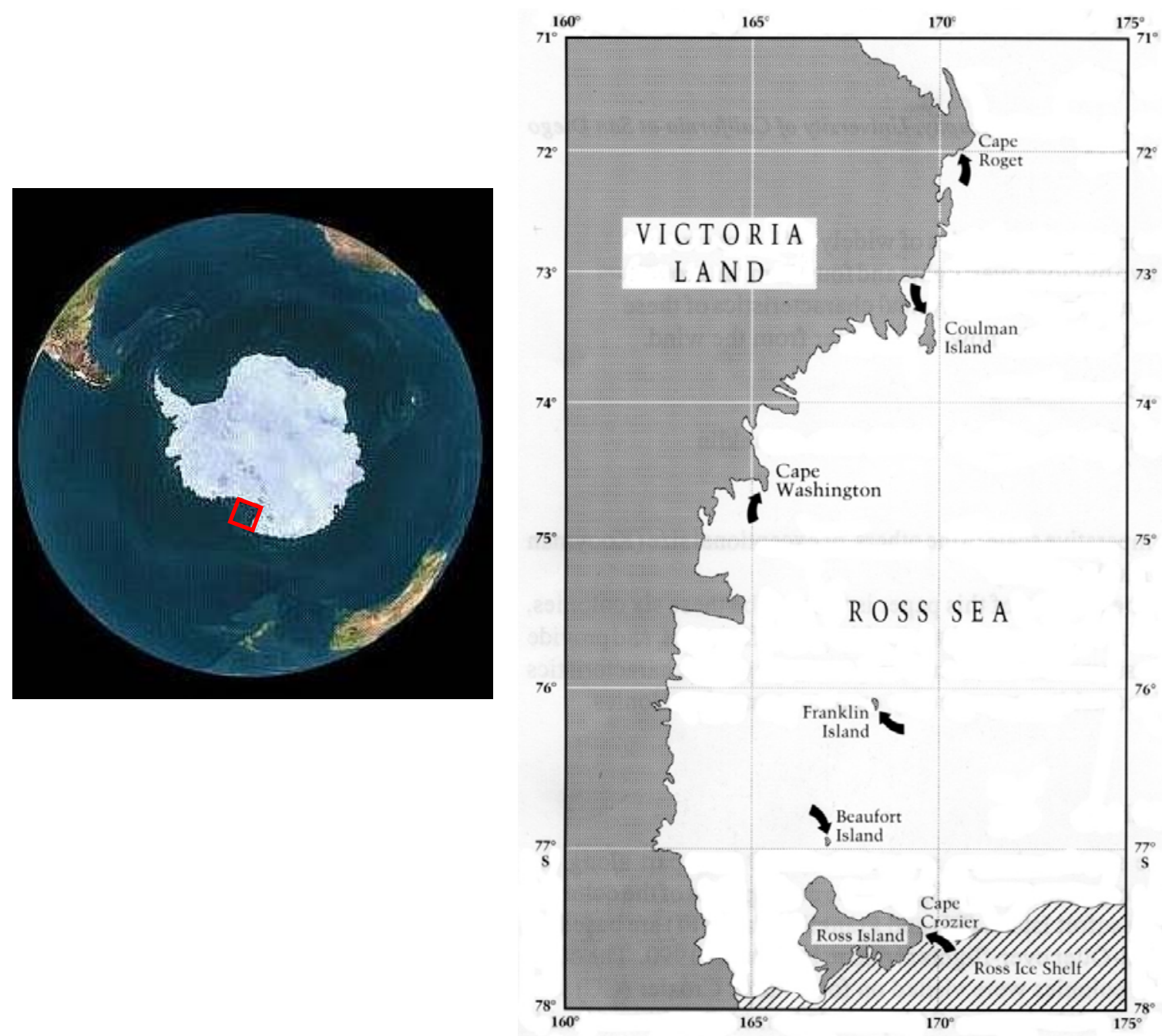

Figure1. Cape Crozier and secondary sites in the Ross Sea area.

To know the precise grid coordinate of photo-identifiable ground control points in the primary study area, static surveys using Trimble GPS receivers were attempted by the University Navstar Consortium (UNAVCO) science technician Chuck Kurnik in the 2001 summer field season and again by USGS geodesist Larry Hothem during the 2002 summer field season. The researchers compiled an extensive index list of photoidentifiable ground control points for this effort. Due to system mechanical problems during the simultaneous data collection of the static surveys, usable crucial data from the McMurdo Continuous Operating Reference Station (CORS) were unavailable. The simultaneous data collection of the CORS would have yielded the RINEX (Receiver Independent Exchange) formatted files (range and carrier phase or binary measurements, 
predicted orbital coordinates or ephemeris data, and site information files) needed for post-processing the static survey collected data.

\section{Data Preparation and Entry}

The researchers developed several image data sets from the source material to generate integrated color raster and vector files. The overall data preparation consisted of image processing, point data entry and retrieval phases. See Figure 2.

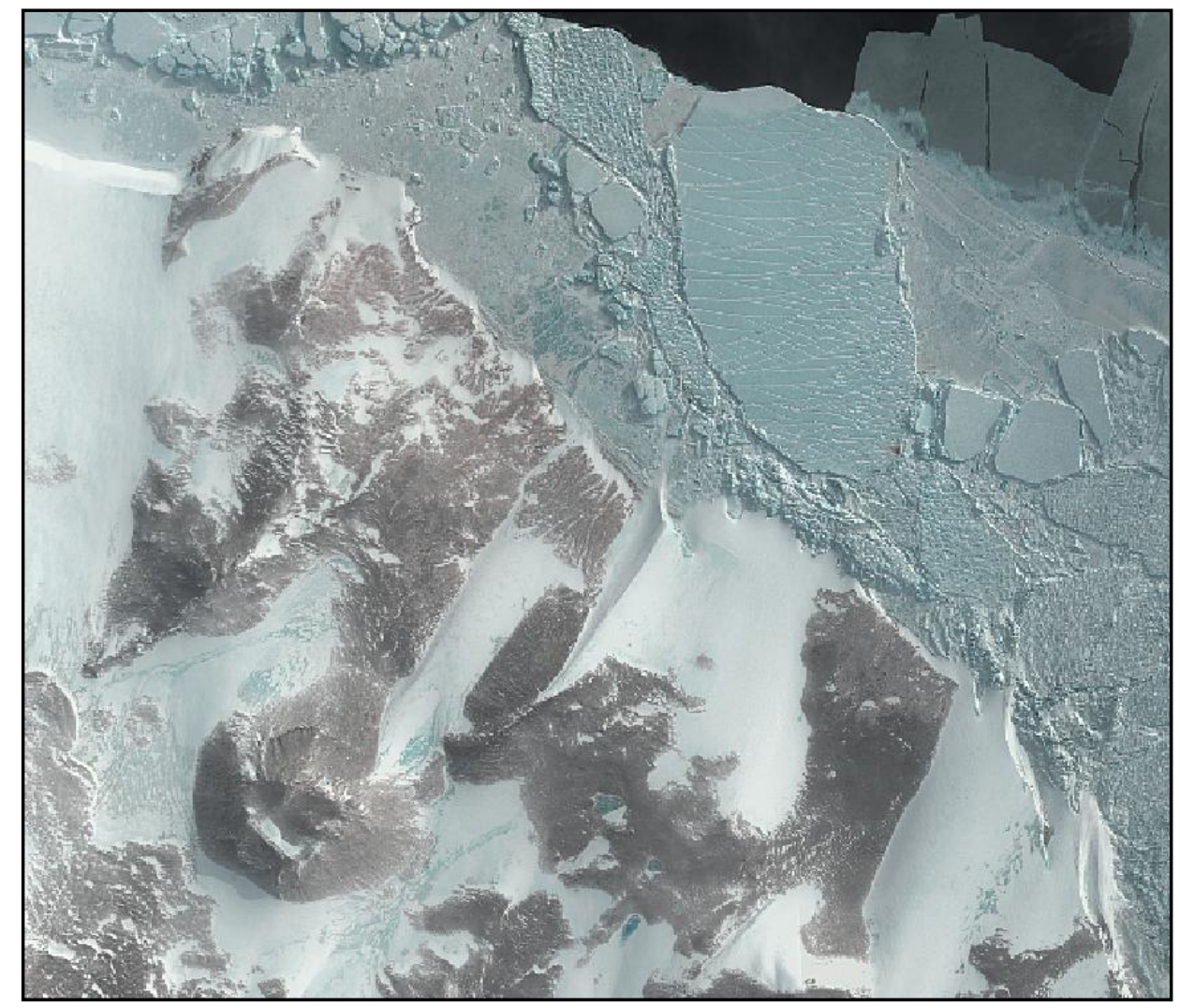

Figure 2. Merged image derived from 2002 QuickBird pan and multispectral data.

\section{Image processing}

To merge the Quickbird 0.60-m panchromatic image files, each 4-m Quickbird multispectral image was interpolated to $0.60-\mathrm{m}$ pixels. The geometric registration routine converted the 4-band multispectral data to the same pixel size as the panchromatic image. This routine required the registration of the multispectral data using image-to-image $x$ and $y$ control points. Using the appropriate panchromatic image as the base file, the routine developed a planimetric transformation by selecting several well-distributed control points in the base and correlating their UTM coordinates to corresponding $x$ and $y$ positions in each multispectral image. These points were then applied in a least-square regression analysis to derive a second-order polynomial transformation of a representative multispectral band with less than a 2-pixel root mean square error. 
Following the transformation to 60 by 60 -cm output pixels, the researchers used a high pass box filter to enhance higher spatial frequency components of each output color image. Owing to the unsuccessful collection of geodetic ground control data, digital terrain elevation data needed for the ortho-rectification of the Quickbird images were not available for this project.

\section{Point data entry and retrieval}

To count the Emperor penguins the researchers created a point file or overlay over each raster image backdrop. Each penguin was collected as a point which was then automatically logged and tallied in a feature and attribute file. Point files were individually displayed in contrasting colors over the image backdrop and systematically inspected for proper fit. The use of the "flicker" and "swipe" toggle switches to adjust the color display provided a quick visual check of the registration between the point file and the raster image (Sanchez, 1999). The researchers performed a systematic sampling by reviewing each point file over the image backdrop in subsections and visually comparing graphic plots of the overlays with the corresponding raster images. Any point feature in the image that appeared to be missing, altered, or unidentifiable, was marked for further inspection.

The visual comparison of in-the-field data provided a good comparison of any spatial inconsistencies such as mismatching, overcounts and undercounts. After inspecting the data collection results, we exported the data to the ArcGIS for display and further verification of the results. Once compiled we stored the spatial database on compact disks.

\section{Review and Analysis}

\section{Spatial resolution}

We compared each habitat between images derived from existing civilian sensor and other sources. The results varied from negligible to moderate differences in informational content and interpretability. Although QuickBird imagery has sufficient spatial data to detect Emperor penguin groups, it will need to be supplemented with NCAP data to accurately validate penguin counts (figure. 3). Applying both sources of imagery, counts of group size from imagery are comparable to counts made by observers on the ground.

\section{Positional accuracy}

QuickBird only guarantees a horizontal accuracy of 200 meters from its true position in Antarctica and standard vertical positioning coordinates or digital terrain elevation data are not available. We examined absolute orientation of photo-identifiable features using horizontal positional coordinates in the imagery and ground reference points. Differences between feature positions and the corresponding ground reference points were compared. The measured horizontal difference was $>200$ meters from the ground-level positions of 
the existing reference points, insufficient horizontal positional accuracy to meet largescale map accuracy requirements.

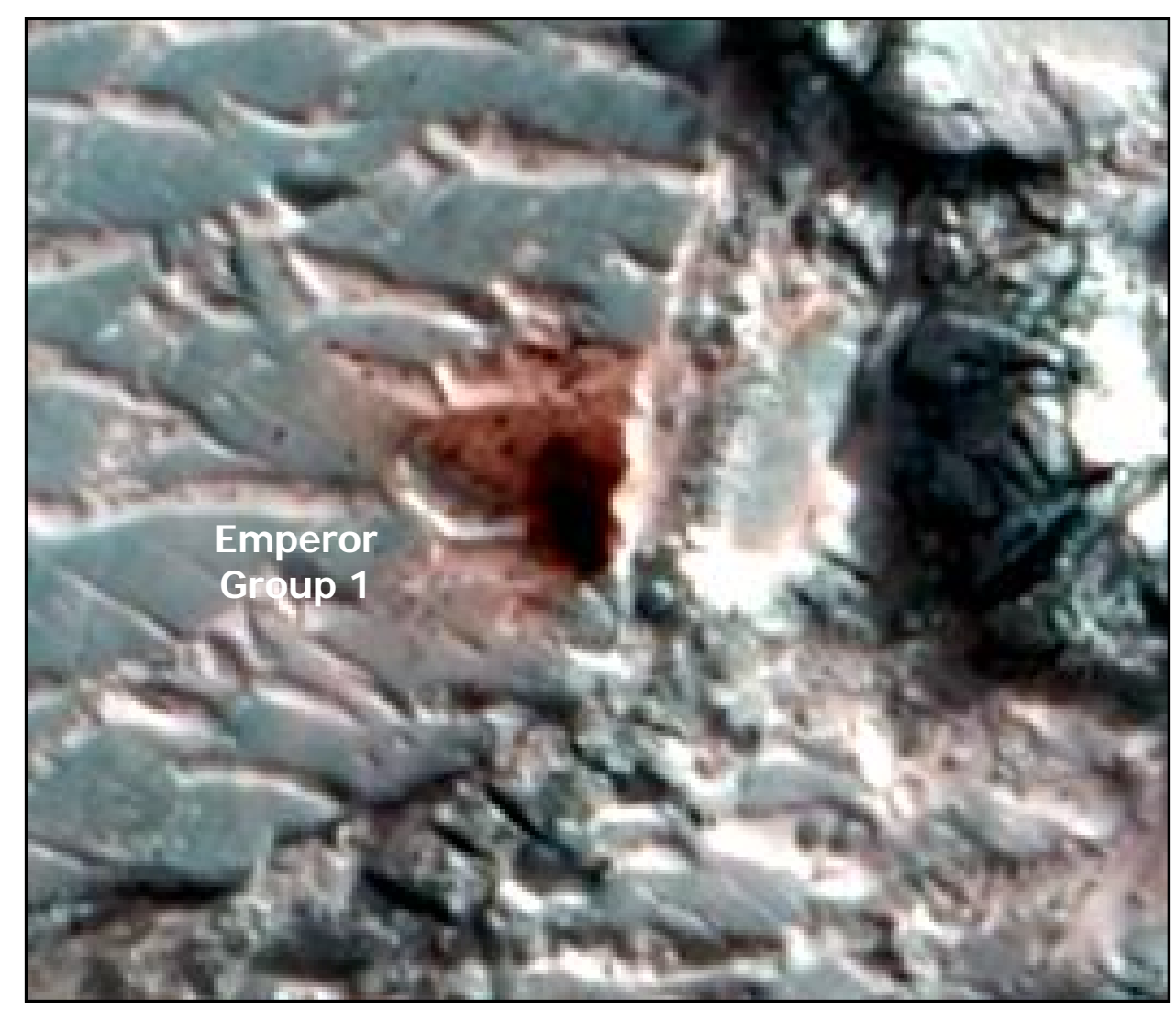

Figure 3. Quickbird 0.60-m pixel resolution at $\approx 1: 750$ frame scale.

\section{Findings}

The findings of this study show that the spatial data collection assets of the commercial satellites may not meet the stringent requirements for mapping detailed changes in penguin habitats. Achieving such stringent requirements may have to come from lowaltitude aerial photography (in particular, airborne integrated digital mapping GPS/Inertial systems for direct geopositioning). Because sufficient geodetic ground control data was not available for this study developing numerical models for population counts from digital terrain elevation data and ortho-rectified imagery could not be examined. However, this study does demonstrate the possibilities of commercial satellite data and NCAP resources for long-term archiving and environmental monitoring. The potential benefits of adding these data to mapping wildlife habitats in Antarctica are far reaching and include continuous year-round coverage. A wide array of NCAP resources data increases the opportunity for NSF researchers to make better-informed decisions. 


\section{Recommendations}

Although the results of this study do not support large-scale mapping, the commercial satellite and NCAP data can provide valuable data resources for archiving and long-term environmental monitoring. We recommend continuing research for examining optimum levels of both data resources to meet accuracy requirements of more detailed penguin censuses and the long-term monitoring of Antarctic wildlife habitats so scientist can better study and understand the cause and effect of changes over time. In addition, research in the transportability of procedures to TNP application is recommended. It is important for researchers to realize the limits of these data sources and to balance the criteria for their use against practical considerations of doing short or long-term environmental studies in the Antarctic.

\section{Acknowledgment}

The authors would like to thank Polly Penhale and Scott Borg of the NSF for supporting this study.

\section{References}

Civil Applications Committee, February 2002, Global Fiducials Program, CAC Secretariat, Reston, Virginia.

Civil Applications Committee, July 2001, The Civil Applications Committee, CAC Secretariat, Reston, Virginia.

Civil Applications Committee, (no date shown), Rapid Exploitation System, CAC Secretariat, Reston, Virginia.

Civil Applications Committee, July 2001, Imagery Derived Products, CAC Secretariat, Reston, Virginia.

Robertson, G., 1990, “Huddles,” Australian Geographic Journal, 1:76-97

Sanchez, R.D., 1999, GPS and GIS-Based Data Collection and Image Mapping in the Antarctic Peninsula, USGS Open-File Report 99-402. 